\title{
Investigation of sperm-induced cervical leucocytosis by a double mating study in rabbits
}

\author{
N. J. Taylor \\ Department of Zoology and Comparative Physiology, University of Birmingham, P.O. Box 363 , \\ Birmingham B15 2TT, U.K.
}

\begin{abstract}
Summary. The cervices of 2 normally mated does at $1 \mathrm{~h}$ post coitum were examined for the presence of leucocytes and compared with the cervix of an unmated doe. Cervical leucocytosis $\left(50 \times 10^{6}\right.$ leucocytes) was demonstrated following mating with either of 2 bucks, but not in the unmated doe. Each of 16 does was single-mated with 2 bucks whose offspring could be distinguished clearly. The interval between first and second mating was $0,0 \cdot 5,1$ or $4 \mathrm{~h}$. One buck produced 68 offspring, the other buck produced 37. Cervical leucocytosis did not impair the fertility of the second buck even if it was the inferior buck; so fertilizing spermatozoa may traverse the cervices, even through large numbers of leucocytes. The differences in fertility between spermatozoa from different bucks during competitive fertilization may reflect different capacitation times of these spermatozoa.
\end{abstract}

\section{Introduction}

Cervicitis is frequently diagnosed in women during examination of routine cervical smears. Many of these smears contain not only numerous leucocytes, but also spermatozoa ( $P$. Bromwich, unpublished observations). It has been said that the fate of most spermatozoa in the female tract, other than mechanical expulsion (Morton, 1970), is phagocytosis by leucocytes (Austin, 1957, 1960; Bedford, 1965). Phillips \& Mahler (1977) described leucocytosis in the rabbit vagina induced by copulation, and phagocytosis of spermatozoa. Tyler (1977a) reported an immense leucocytosis in the rabbit cervix, within $30 \mathrm{~min}$ of mating, in response to spermatozoa but not seminal plasma. Mattner $(1969 \mathrm{a}, \mathrm{b})$ also described phagocytosis of spermatozoa in the cervical lumen. Smallcombe \& Tyler (1980) further showed that this sperm-induced leucocytosis was associated with considerable secretion of IgG into the cervix. There is also evidence that sperm-induced leucocytosis occurs in the human cervix (I. Pandya, unpublished observations).

Tyler (1977b) and Cohen \& Tyler (1980) suggested that the cervical leucocytosis removes excess spermatozoa from the female tract and prevents cervical passage after the fertilizing spermatozoa have entered, so that the female does not become sensitized to spermatozoa. Since most spermatozoa remaining in the female tract are phagocytosed by leucocytes, this leucocytosis could be functionally compared with the copulatory plug of rodents, being a device to prevent other males mating successfully with the same female (see review by Parker, 1970).

The present experiments were performed to examine the effects of this induced leucocytosis on the success of later spermatozoa, inseminated during a second mating at various intervals after the first. 


\section{Materials and Methods}

Experiment 1 . Two male rabbits were selected so that their offspring were readily and certainly distinguishable. Buck L carried full Lop ears (an effectively dominant character) and Buck $\mathbf{N}$ had ears of normal length. The Dutch does used had the following coat colour genetics (according to Sandford, 1957): aa, b/B, du ${ }^{\mathrm{d}}$. Buck $\mathrm{N}$ was agouti coloured and always produced either agouti offspring or offspring showing some Dutch pattern and thus was presumed to be: A, BB, Du du, en en. Buck L was sooty fawn English pattern, and its offspring were all black, black and white English pattern or sooty fawn; the buck was therefore presumed to be: $a a, \mathrm{Bb}$, En en, Du Du.

Both males were allowed to copulate once only with each of 16 parous Dutch does, with repeat matings until a live litter was produced from each doe. The interval between first and second mating was $0,0 \cdot 5,1$ or $4 \mathrm{~h}$, and 4 does were mated twice for each time. The bucks were alternated so that each buck mated first at two of the times. The does were permitted to raise their litters for 6 weeks, by which time there was no question of the paternity of the offspring (coat colour markers were distinguishable soon after birth and ear length differences became evident at 2-3 weeks).

Experiment 2. The cervices of 3 other Dutch does were also examined in situ, and taken for histology, $1 \mathrm{~h}$ after a single mating with either buck or from an unmated doe. The cervix was fixed in Bouin's fluid and 5-7 $\mu \mathrm{m}$ paraffin wax sections were stained with Cason's modification of Mallory's Triple stain or Celestin-Blue/Masson's Triple Stain and examined by bright-field microscopy for the presence of spermatozoa and leucocytes.

\section{Experiment 1}

\section{Results}

The offspring produced by each buck were clearly distinguishable from one another, and the litters were of mixed paternity except for one litter at time $0 \mathrm{~h}$. The coat colour of the offspring always confirmed the presumed coat colour genetics of the parents. The number of offspring from each buck for each mating is given in Text-fig. 1; of the 105 offspring, 68 were from Buck $\mathrm{N}$ and 37 from Buck L (only 4 out of 7 matings produced live offspring after a 4-h difference between copulations and unfortunately 3 of these were for matings with Buck L first).

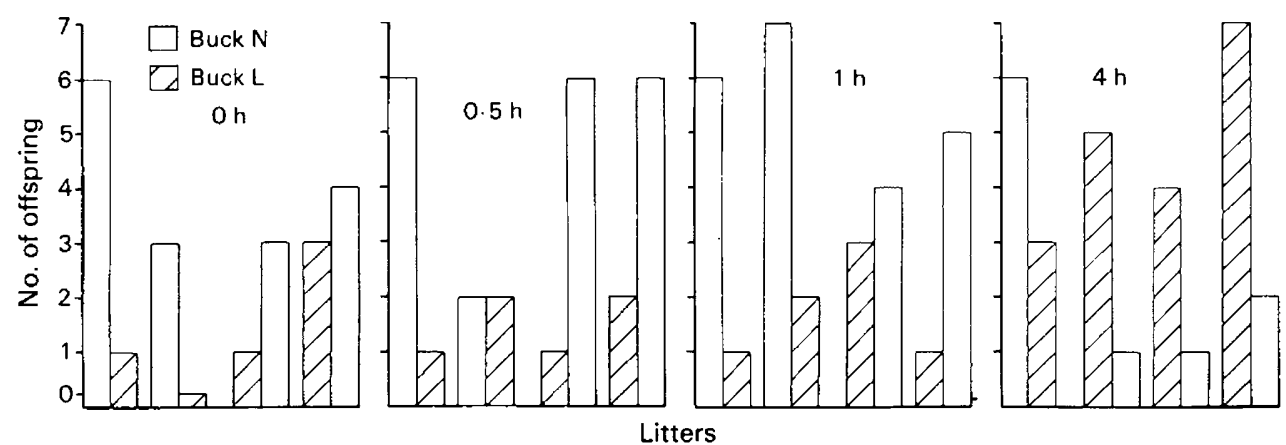

Text-fig. 1. Results of the double mating experiment. Each double mating is represented by two columns; the number of offspring for each buck is given in the order of mating.

For intervals of $0,0.5$ and $1 \mathrm{~h}$, Buck $\mathrm{N}$ produced significantly more offspring than did Buck L (Table 1). However, for each buck, the order of mating made no significant difference to the number of offspring produced. The second buck always contributed to the litter (except once at 
Table 1. Mean \pm s.d. of offspring (no. in parentheses) produced by each buck, mating first or second less than $4 \mathrm{~h}$ apart

\begin{tabular}{lcll}
\hline & Buck N & \multicolumn{1}{c}{ Buck L } \\
\hline Mating 1st & $5 \pm 2.0(30)$ & $1.83 \pm 0.98(11)$ & $P=0.01-0.001$ \\
Mating 2nd & $4.67 \pm 1.21(28)$ & $1.17 \pm 0.75(7)$ & $P<0.001$ \\
\hline
\end{tabular}

0 h). With a 4-h interval and Buck $\mathrm{L}$ first, the number of offspring produced by Buck $\mathrm{N}$ was reduced, the majority of the litter coming from Buck L (Text-fig. 1).

\section{Experiment 2}

Visual examination of the cervix from does mated with either buck $1 \mathrm{~h}$ previously showed them to be very oedematous, compared with the cervix of an unmated doe. Histological sections showed spermatozoa in the cervical lumen and crypts, and a massive invasion of leucocytes into the cervical tissue. There were more than $10^{6}$ leucocytes per $\mathrm{mm}^{3}$ in the ectocervices around the os, and the numbers declined nearer the vaginal wall. There were some $20-30 \times 10^{6}$ leucocytes around each cervical os, a total of about $50 \times 10^{6}$ leucocytes distributed within the 2 cervices. The method of fixation did not permit the assessment of additional leucocytes in the lumen since most spermatozoa and leucocytes were washed away during fixation. Sections of the cervix from the unmated doe showed no leucocytosis, always $<500$ per $\mathrm{mm}^{3}$ even at the ectocervix.

\section{Discussion}

The second buck contributed to the offspring produced by the double matings, even when there was a 4-h interval between matings. Examination of the cervix of does mated $1 \mathrm{~h}$ previously with either buck showed that leucocytosis occurred as described by Tyler (1977a). It is reasonable to assume that a similar leucocytosis also occurred during the double matings, i.e. between first and second matings at times $\geqslant 0.5 \mathrm{~h}$. The leucocytosis, involving at least $50 \times 10^{6}$ cells in passage through the cervical epithelium at $1 \mathrm{~h}$ p.c., did not then impair the fertility of the second buck.

Buck N was superior when in competition (see Beatty, 1960); however, Beatty only used 'heterospermic insemination': the ejaculates of two bucks were mixed and artificially inseminated into a female (comparable to time $0 \mathrm{~h}$ in this double mating regimen). Dziuk (1965) utilized a double mating series to determine capacitation time for rabbit spermatozoa. He varied ovulation time with respect to the time of first mating and found that capacitation took a minimum of $6 \mathrm{~h}$. Dziuk's (1965) results show that the second buck was able to contribute to the offspring produced. It is possible that the spermatozoa from our superior buck became capacitated more rapidly than did those of the inferior buck (Mortimer, 1978) and thus were always at an advantage except when the superior buck was $4 \mathrm{~h}$ after the first; presumably the 'inferior' spermatozoa were able to become capacitated first. It is surprising, however, that the inferior buck (L) should sire 3 offspring when second at this time interval; this clearly shows that at least a few of his spermatozoa had become effective more rapidly than predicted by this simple view.

It has been assumed that leucocytes in the female genital tract phagocytose excess spermatozoa, possibly to prevent immunization of the female (Johnson, 1973; Tyler, 1977b). The sperm-induced leucocytosis in the rabbit cervix results in more than $50 \times 10^{6}$ leucocytes in the cervical tissue even at $1 \mathrm{~h}$ p.c. (and presumably many more in the vaginal lumen as shown by Phillips \& Mahler, 1977), but does not exclude spermatozoa from a second mating, even if they are from an 'inferior' buck. This combined population of leucocytes probably exceeds even two ejaculates in number. 
Cohen \& Gregson (1978) showed that the first few spermatozoa to migrate through a column of ovulatory human cervical mucus failed to bind serum IgG as visualized by immunofluorescence. Similarly, Cohen \& Tyler (1980) found that the first few spermatozoa to pass through the rabbit cervix were uncoatable by $\operatorname{IgG}$ and were also very fertile when transferred to the uteri of recipient does. It is therefore possible that the cervix normally only permits a few spermatozoa to reach the site of fertilization, perhaps discriminating on IgG binding affinity (Cohen \& Werrett, 1975; but see Taylor, 1982). A second ejaculate could be similarly discriminated in that the majority of its sperm population might be phagocytosed, but a few spermatozoa would pass through the cervix.

Whatever mechanisms are involved, spermatozoa are able to pass through leucocytes to fertilize eggs, i.e. some spermatozoa are not phagocytosed. 'Cervicitis' in women may therefore be a physiological rather than a pathological phenomenon, and in any case need not prevent sperm passage. Whether cervical leucocytosis is a non-specific response to foreign protein or a necessary part of the complex process leading to conception is unclear.

I thank Dr Judy Cohen for the loan of Buck L, Dr Jack Cohen for helpful advice, and Toxicol Laboratories Ltd for donating the does used in this study. This work was supported by an S.E.R.C. Studentship.

\section{References}

Austin, C.R. (1957) Fate of spermatozoa in the uterus of the mouse and rat. J. Endocr. 14, 335-342.

Austin, C.R. (1960) Fate of spermatozoa in the female genital tract. J. Reprod. Fert. 1, 152-156.

Beatty, R.A. (1960) Fertility of mixed semen from different rabbits. J. Reprod. Fert. 1, 52-60.

Bedford, J.M. (1965) Effect of environment on the phagocytosis of rabbit spermatozoa. J. Reprod. Fert. 9, 249-256.

Cohen, J. \& Gregson, S. (1978) Antibodies and sperm survival in the female genital tract. In Spermatozoa, Antibodies and Infertility, pp. 17-31. Eds J. Cohen \& W. F. Hendry. Blackwell, London.

Cohen, J. \& Tyler, K.R. (1980) Sperm populations in the female genital tract of the rabbit. J. Reprod. Fert. 60 , 213-218.

Cohen, J. \& Werrett, D.J. (1975) Antibodies and sperm survival in the female tract of the mouse and rabbit. J. Reprod. Fert. 42, 301-310.

Dziuk, P.J. (1965) Double mating of rabbits to determine capacitation time. J. Reprod. Fert. 10, 389-395.

Johnson, M.H. (1973) Physiological mechanisms for the immunological isolation of spermatozoa. $A d v$. Reprod. Physiol. 6, 279-323.

Mattner, P.E. (1969a) Differential leucocyte response to spermatozoa in the cervix and uterus of ewes. $J$. Reprod. Fert. 18, 297-303.

Mattner, P.E. (1969b) Phagocytosis of spermatozoa by leucocytes in bovine cervical mucus in vitro. $J$. Reprod. Fert. 20, 133-134.
Mortimer, D. (1978) Selectivity of sperm transport in the female genital tract. In Spermatozoa, Antibodies and Infertility, pp. 37-53. Eds J. Cohen \& W. F. Hendry. Blackwell, London.

Morton, D.B. (1970) On the transport of spermatozoa in the female tract. Ph.D. thesis, University of Liverpool.

Parker, G.A. (1970) Sperm competition and its evolutionary consequences in the insects. Biol. Rev. 45, 525-568.

Phillips, D.M. \& Mahler, S. (1977) Leucocyte emigration and migration in the vagina following mating in the rabbit. Anat. Rec. 189, 45-60.

Sandford, J.C. (1957) The Domestic Rabbit, pp. 143144. Crosby Lockwood \& Son, London.

Smallcombe, A. \& Tyler, K.R. (1980) Semen-elicited accumulation of antibodies and leucocytes in the rabbit female tract. Experientia 36, 88-89.

Taylor, N.J. (1982) Equivalence of 'non-IgG binding' and 'acrosomeless' sperm populations from the female genital tract of the rabbit. J. Reprod. Fert. 64, 181-184.

Tyler, K.R. (1977a) Histological changes in the cervix of the rabbit after coitus. J. Reprod. Fert. 49, 341-345.

Tyler, K.R. (1977b) Studies on the interactions between spermatozoa, immunoglobulins, and the female reproductive tract in the rabbit and human. Ph.D. thesis, University of Birmingham.

Received 16 November 1981 